\title{
On-line liquid chromatography-mass spectrometry with dilution line to achieve large volume urine injection for the improvement of sensitivity
}

\author{
Min Liu ${ }^{\mathrm{a}}$, Wei Yan ${ }^{\mathrm{a}}$, Jin-Ming Lin ${ }^{\mathrm{a}, \mathrm{b}, *}$, Yuki Hashi ${ }^{\mathrm{a}}, \mathrm{Li}$-bin Liu ${ }^{\mathrm{a}}$, Yanlin Wei ${ }^{\mathrm{a}}$ \\ a State Key Laboratory of Environmental Chemistry and Ecotoxicology, Research Center for Eco-Environmental Sciences, \\ Chinese Academy of Sciences, P.O. Box 2871, Beijing 100085, China \\ b The Key Laboratory of Bioorganic Phosphorus Chemistry \& Chemical Biology, Department of Chemistry, Tsinghua University, Beijing 100084, China
}

\section{A R T I C L E I N F O}

\section{Article history:}

Received 20 December 2007

Received in revised form 1 April 2008

Accepted 6 May 2008

Available online 21 May 2008

\section{Keywords:}

Large volume injection

Dilution line

On-line

Liquid chromatography-mass spectrometry

Estrogens

Spiked urine samples

\begin{abstract}
A B S T R A C T
A unique automated on-line high-performance liquid chromatography-mass spectrometry (LC-MS) method was developed allowing injection of a large volume of urine for the improvement of sensitivity using estrogens as analytes. The urine sample was precipitated by acetonitrile (sample:acetonitrile, 1:2, $\mathrm{v} / \mathrm{v}$ ) to remove most proteins. Then the supernatant was directly delivered at $0.3 \mathrm{~mL} / \mathrm{min}$ by a pump, which broke through the limit of autosampler with fixed loop. Then the sample was loaded onto a restricted access media (RAM) pre-column after on-line dilution with $\mathrm{NH}_{4}$ Ac solution which was delivered by another pump under high flow-rate. After the addition of on-line dilution line, the content of organic solvent in the sample aliquot was sharply decreased so that the analytes were effectively trapped by precolumn. In addition, another 6-port valve was added to selectively deliver the effluent containing analytes into MS, which minimized the pollution of the MS and matrix effect. After optimization of the condition of extraction method, $3 \mathrm{~mL}$ sample (containing $1 \mathrm{~mL}$ urine) could be successfully enriched. The injection volume increased 10 times compared with conventional on-line LC-MS methods for biofluid analysis, significantly improving sensitivity. Moreover, no obvious increase of column pressure was observed after 300 injections. The method was validated by spiking urine. Linearity was determined by sample which was in the range of $1-500 \mathrm{ng} / \mathrm{mL}$. The process efficiency ranged from 70.2 to $106 \%$ with RSDs less than $15 \%$ with the exception of a few analytes. The limit of detection (LOD) and quantification (LOQ) ranged from 0.3 to $2 \mathrm{ng} / \mathrm{mL}$ and 1 to $8 \mathrm{ng} / \mathrm{mL}$, respectively, corresponding a decrease of $1-2$ orders of magnitude compared with those of off-line and on-line methods.
\end{abstract}

(c) 2008 Elsevier B.V. All rights reserved.

\section{Introduction}

Liquid chromatography-mass spectrometry (LC-MS) has widely been used for fast and sensitive determination of medicines [1,2] and endogenous compounds [3] in biological fluids. However, time-consuming and off-line sample pre-treatment becomes the bottleneck of this technique. On-line LC-MS is increasingly developed and applied to routine analysis as a high throughput technique $[4,5]$. The approach was proved to be highly effective; however, the lifetime of the extraction column was limited when regular reversed-phase packing material was used, since residual protein caused high backpressure. Li et al. [6] reported that when $100 \mu \mathrm{L}$ plasma was consecutively injected over 5 times, the recoveries obviously decreased. To the increase lifetime of extraction column and avoid clogging of the column and system, sample dilution

\footnotetext{
* Corresponding author. Fax: +861062792343.

E-mail address: jmlin@mail.tsinghua.edu.cn (J.-M. Lin)
}

or protein precipitation was performed by some groups [7]. Kuklenyik [8] also found that $C_{18}$ extraction column could be reused for 10-12 times with injection of $100 \mu \mathrm{L}$ plasma after diluting 3 times.

To be more effectively deproteinated in biofluid, several kinds of pre-columns were developed. Turbulent flow chromatography (TFC) was developed based on the use of extraction column packed with large particles (typically 30-50 $\mu \mathrm{m}$ ). It permitted the loading sample at high flow-rate without generating high backpressure. Under this condition, large molecules such as proteins could easily pass through the pre-column and enter into the waste $[9,10]$. Wu et al. [11] demonstrated that under high (turbulent) flow-rate, the system can tolerate several hundred injections with $100 \mu$ L plasma. Nevertheless, conventional extraction supports would be rapidly damaged under laminar flow-rate. Monolithic phase, another type of column, was also suitable for the direct injection of biological fluids [12]. Plumb et al. [13] have demonstrated that monolithic supports could tolerate several milliliters of plasma without degradation of significant performance. 
Recently, restricted access media (RAM) for solid-phase extraction (SPE) has also been used for high-throughput bioanalysis $[14,15]$. The outer surface of RAM contains hydrophilic groups and reversed-phase supports are bonded onto the internal surface. Macromolecules, such as proteins, could be excluded and flushed away by the size exclusion principle. While small target molecules could penetrate into the pores and be retained by hydrophobic interaction. This method can tolerate more biological fluid than reversal-phase materials. Needham et al. [16] quantified the anxiolytic agent CP-93 393 in plasma using RAM column as the extraction column. More than 200 direct plasma injections of $100 \mu \mathrm{L}$ were performed.

Although such methods have been applied to direct biofluid analysis, they could not completely meet the requirement of analysis due to trace concentrations of analytes in biofluid. In order to increase the sensitivity of the method, some improvements were made. For example, the addition of organic acid to mobile phase was used for the improvement of the positive ionization [17]. Such methods could enhance the sensitivity of the method to some extent; however, they were ultimately limited by the intrinsic quality of the instruments used. Under this situation, enrichment of larger volume samples seems to be the only fundamental method to improve sensitivity and decrease the limit of detection (LOD). For the on-line LC-MS method, that is to increase injection volume of single analysis. However, the injection volume is generally less than $100 \mu \mathrm{L}$ for on-line LC-MS. There are few report on the development of large volume injection (LVI) to improve the sensitivity $[18,19]$. Since large volumes of complex biological fluid tends to introduce residual protein, which may induce high column pressure and matrix signal suppression. In addition, LVI is liable to cause column overloading, peak broadening and separation deterioration. To overcome the drawbacks mentioned above, we have established an on-line LC-MS method using RAM column as extraction column to determine bisphenol A and 4-octylphenol in serum. Good linearity was shown between the peak area and injection volume in the range of 25-200 $\mu \mathrm{L}$ [20]. However, upon increasing the injection volume, the lifetime of column was shortened sharply. Therefore, the limited injection volume was not enough to improve the sensitivity. It is necessary to explore new method to further increase injection volume and decrease the detection limit of on-line LC-MS method for the analysis of biofluid.

In the present paper, we attempted to establish a novel method to achieve large volume urine analysis by on-line LC-MS using estrogens as analytes. Evaporation of the extracted sample was unnecessary. The method developed was validated by recovery, precision and limit of detection with spiked urine sample. Lastly, it was compared with several traditional methods including off-line and on-line methods.

\section{Experimental}

\subsection{Chemicals and reagents}

Water was obtained by purification of de-ionized water through a Barnstead system (Dubuque, IA, USA). Methanol and acetonitrile (HPLC grade) were purchased from Fisher (Fair Lawn, NJ, USA). Estrogens as shown in Fig. 1, including 17 $\beta$-estradiol, estriol, 2-hydroxyestrone, $16 \alpha$-hydroxyestrone, 2 -methoxyestrone, 2-hydroxyestradiol, estrone, were purchased from Sigma-Aldrich (St. Louis, MO, USA). Ammonium acetate was purchased from Wako (Osaka, Japan). Stock solutions of estrogens at $1.0 \mathrm{mg} / \mathrm{mL}$ were prepared in acetonitrile and working standard solutions were prepared at various concentrations by appropriate dilution of the stock solutions. These solutions were stored at $-25^{\circ} \mathrm{C}$.

\subsection{Sample preparation}

Urine samples were collected from healthy adult men after getting up in the morning and respectively stored in $10 \mathrm{~mL}$ bottles at $-25^{\circ} \mathrm{C}$. Before use, the urine samples were thawed at room temperature and spiked with the diluted standard solutions daily. Then protein precipitation was performed by acetonitrile (sample:acetonitrile, $1: 2, \mathrm{v} / \mathrm{v}$ ), the aliquot was vortexed for $1 \mathrm{~min}$ and centrifuged at $4000 \mathrm{rpm}$ for $10 \mathrm{~min}$. The supernatant was loaded onto the pre-column.

\subsection{Apparatus}

A Shimadzu LC-MS 2010A system was employed. It consisted of five LC-10ADvp pumps, a DGU-14A degasser, a SIL-HTc autosampler and a single quadrupole MS. Data acquisition and processing were performed with the LC-MS solution Ver 3.0 Workstation. The chromatographic separation was performed on Symmetry- $\mathrm{C}_{18}$ column $(150 \mathrm{~mm} \times 2.0 \mathrm{~mm}, 5 \mu \mathrm{m})$ purchased from Waters (Milford, MA, USA). RAM pre-column, Shim-pack MAYI-ODS $(10 \mathrm{~mm} \times 4.6 \mathrm{~mm}$, $50 \mu \mathrm{m}$ ) was obtained from Shimadzu (Kyoto, Japan).<smiles>CC12CCC3c4cc(O)c(O)cc4CCC3C1CCC2O</smiles>

2-hydroxyestrone (2-OHE 1 ) m/z 285<smiles>CC12CCC3c4ccc(O)cc4CCC3C1CC(O)C2O</smiles><smiles>CC12CCC3c4cc(O)c(O)cc4CCC3C1CCC2O</smiles>

2-hydroxyestradiol (2-OHE 2 ) m/z 287<smiles>COc1cc2c(cc1O)CCC1C2CCC2(C)C(O)CCC12</smiles>

2-methoxyestrone (2-MeOE 1 ) m/z 299

$16 \alpha$-hydroxyestrone $\left(16 \alpha-\mathrm{OHE}_{1}\right) \mathrm{m} / \mathrm{z} 285$<smiles>CC12CCC3c4ccc(O)cc4CCC3C1CCC2O</smiles>

estrone $\left(E_{1}\right) \quad \mathrm{m} / \mathrm{z} 269$<smiles>CC12CCC3c4ccc(O)cc4CCC3C1CCC2O</smiles>

$17 \beta$-estradiol $\left(\mathrm{E}_{2}\right) \mathrm{m} / \mathrm{z} 271$<smiles>CC12CCC3c4ccc(O)cc4CCC3C1CC(O)C2O</smiles>

estriol $\left(E_{3}\right) \mathrm{m} / \mathrm{z} 287$

Fig. 1. The chemical structure of estrogens. 
(A)
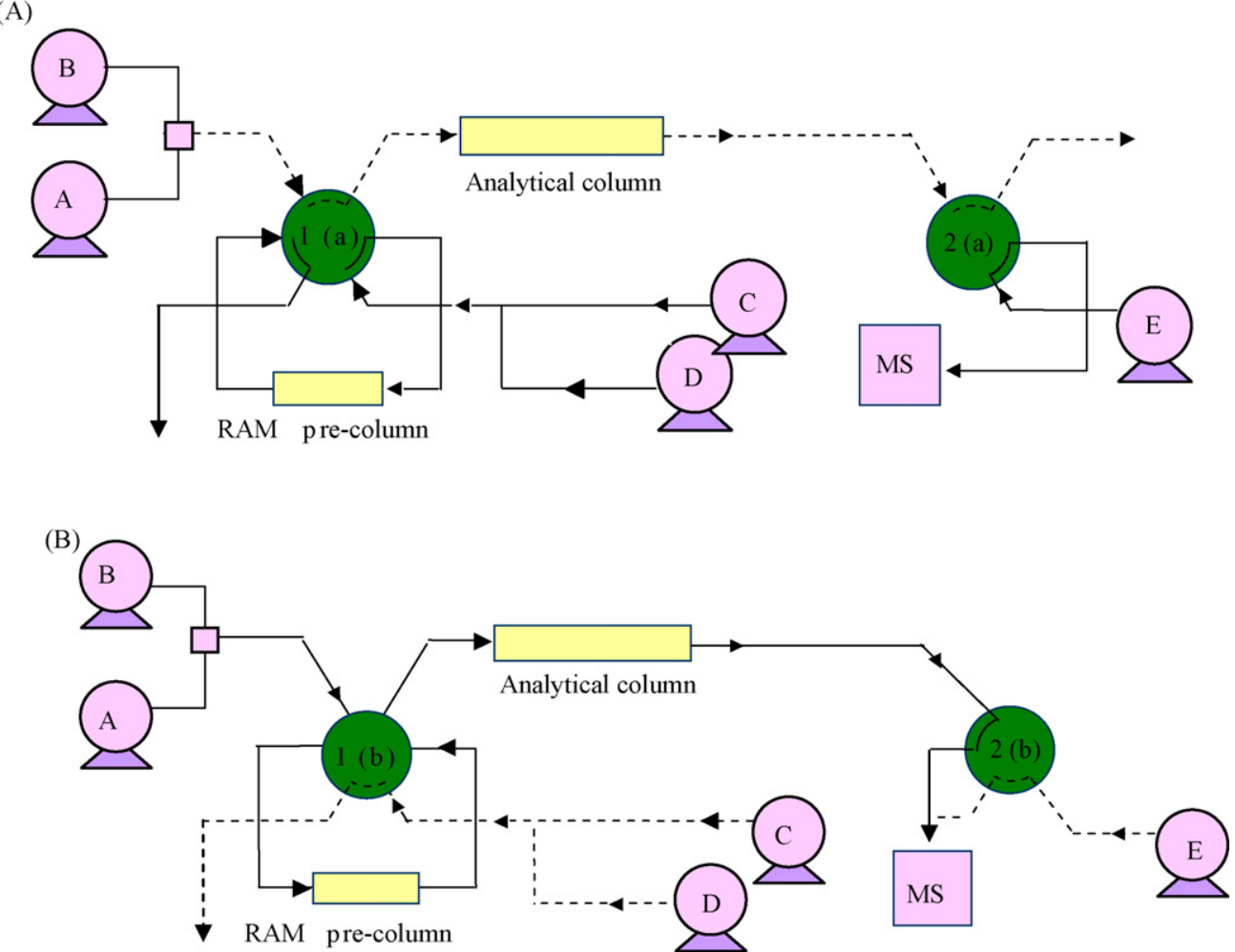

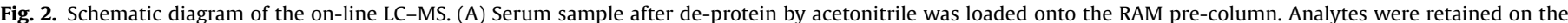

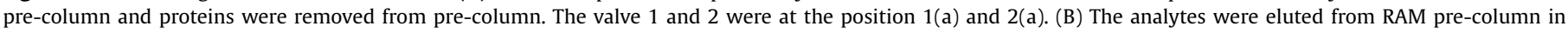

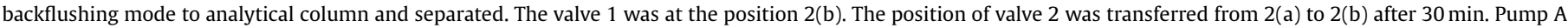
and B was used to deliver analytical mobile phase; Pump C and D were used to deliver sample and dilution mobile phase, respectively.

MS was operated with electrospray ionization (ESI) interface in negative ionization mode: CDL temperature, $260^{\circ} \mathrm{C}$; block heater, $260{ }^{\circ} \mathrm{C}$; nebulizer gas $\left(\mathrm{N}_{2}\right), 1.5 \mathrm{~L} / \mathrm{min}$; drying gas $\left(\mathrm{N}_{2}\right), 0.04 \mathrm{MPa}$; detector voltage, $1.7 \mathrm{kV}$; interface voltage, $4.3 \mathrm{kV}$.

\subsection{On-line sample clean-up and chromatographic conditions}

A diagram of LC-MS system with on-line automated pretreatment was presented in Fig. 2. The procedure for accomplishing LVI was performed as shown in Table 1. First, Pump C was used as the carrier of urine sample after protein precipitation at a flowrate of $0.3 \mathrm{~mL} / \mathrm{min}$. Through a mixing Tee, the sample was diluted with $20 \mathrm{mM}$ ammonium acetate solution provided by pump D at a flow-rate of $2.7 \mathrm{~mL} / \mathrm{min}$. The diluted sample was loaded onto RAM pre-column. The simultaneous process of loading and sample cleanup happened. During this time, the analytical column was re-equilibrated with acetonitrile-water $(10: 90, \mathrm{v} / \mathrm{v})$ at a flow-rate of $0.2 \mathrm{~mL} / \mathrm{min}$ delivered by pump A and B. After the sample was loaded for $10 \mathrm{~min}$, i.e. $3 \mathrm{~mL}$, valve 1 was transferred from position a to $b$. The analytes were then eluted in the back-flush mode, transferred to the analytical column and separated under a gradient condition at a flow-rate of $0.2 \mathrm{~mL} / \mathrm{min}$. The gradient program driven by pump A and B (acetonitrile-water) was as follows: firstly, 10\% (v/v) acetonitrile was held for $5 \mathrm{~min}$, then, the content of acetonitrile was linearly increased from 10 to $50 \%$ in $5 \mathrm{~min}$; and the content of acetonitrile was held at $50 \%$ for $5 \mathrm{~min}$; the content of acetonitrile was linearly increased from 50 to $80 \%$ in $15 \mathrm{~min}$; finally, the content of acetonitrile was linearly decreased to $10 \%$ from 40 to $42 \mathrm{~min}$. While, at $30 \mathrm{~min}$, the switching valve 2 was transferred from position a to b. At $42 \mathrm{~min}$, the valve 1 and 2 were returned to its original position (a). The total analytical time for a single run was $42 \mathrm{~min}$. Both columns were kept at $40^{\circ} \mathrm{C}$.

Table 1

The time procedure of on-line LC-MS method

\begin{tabular}{|c|c|c|c|c|c|c|c|}
\hline Time (min) & Pump A contain (\%) & Pump B contain (\%) & Pump C (mL/min) & Pump D (mL/min) & Pump E (mL/min) & Valve 1 (position) & Valve 2 (position) \\
\hline 0.00 & 10 & 90 & 0.3 & 2.7 & 0.2 & $\mathrm{a}$ & $\mathrm{a}$ \\
\hline 10.00 & - & - & 0 & 0 & - & $\mathrm{b}$ & - \\
\hline 15.00 & - & - & - & - & - & - & - \\
\hline 20.00 & 50 & 50 & - & - & - & - & - \\
\hline 25.00 & 50 & 50 & - & - & - & - & - \\
\hline 30.00 & -- & -- & - & - & 0 & - & $\mathrm{b}$ \\
\hline 40.00 & 80 & 20 & - & - & - & - & - \\
\hline 42.00 & 10 & 90 & - & - & - & - & - \\
\hline
\end{tabular}

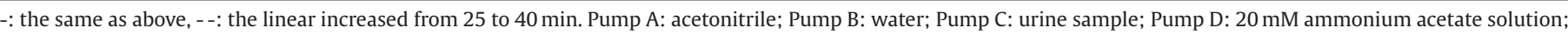
Pump E: acetonitrile. 


\subsection{Method validation}

The linear range, accuracy, precision, limits of detection and quantification (LOQ) were evaluated for the analytical methodology developed. The linearity was determined by spiking urine samples with $1,5,10,50,100$ and $500 \mathrm{ng} / \mathrm{mL}$, respectively. Accuracy and precision were validated by spiking urine samples at three levels of 5,50 and $500 \mathrm{ng} / \mathrm{mL}$. Five replicates were analyzed at each spiked level. LODs and LOQs for each analyte were estimated at the signalto-noise $(\mathrm{S} / \mathrm{N})$ ratio of $3: 1$ and $10: 1$, respectively. The accuracy were calculated by comparing the peak areas obtained from spiked urine samples with those obtained from standard solutions.

\section{Results and discussion}

\subsection{Optimization of an on-line LC-MS method with large volume injection}

After the condition of mobile phase and MS was optimized, the sensitivity was still limited due to the low efficient ionization of estrogens and small injection volume. Usually, the injection volume of most LC-MS methods was set at $10 \mu \mathrm{L}$ or even lower for biofliud. For the improvement of LODs, an off-line and timeconsuming enrichment method is generally used. However, it could not meet the requirement of rapid analysis. In order to achieve high throughput, on-line LC-MS was widely applied. For a given instrument, the increase of injection volume is the fundamental measure to improve sensitivity of on-line LC-MS method. Therefore, it is indispensable to establish an on-line LC-MS method to accomplish large volume injection.

\subsubsection{Protein precipitation}

Firstly, RAM was selected as extraction column. It could selectively retain low molecule analytes and remove macromolecules such as protein. However, the capability of removing protein was limited to small volumes of sample. For large volume biological fluid, it could not completely remove the protein. Based on our research, residual protein is not negligible with increasing injection volume [20]. Therefore, to achieve LVI, most proteins should be removed before injection into the system. Protein precipitation, as a routine and easy method, could remove protein over $90 \%$ with proper precipitants such as acetonitrile, methanol and formic acid and so on [21-23]. However, diverse results were given for different samples considering matrix effect and different analytes. Several precipitants such as acetonitrile, acetone, formic acid and $\left(\mathrm{NH}_{4}\right)_{2} \mathrm{SO}_{4}$ were evaluated, respectively. It was found that the best efficiencies of de-protein were obtained by adding acetonitrile and $\left(\mathrm{NH}_{4}\right)_{2} \mathrm{SO}_{4}$. Since $\left(\mathrm{NH}_{4}\right)_{2} \mathrm{SO}_{4}$ is an inorganic salt, it would be a risk of interface pollution once residual salt enters into MS. Therefore, urine samples were treated with acetonitrile (sample:acetonitrile, $\mathrm{v} / \mathrm{v}, 1: 2$ ) to remove protein. Increasing the amounts of acetonitrile did not obviously change the efficiency of de-protein, the aliquot of sample was diluted instead. The result was in agreement with the data previously reported [22].

\subsubsection{The addition of dilution line}

After getting rid of most protein in urine, the supernatant must be loaded onto the RAM pre-column. For traditional on-line LC-MS system, the sample is carried from an autosampler or manual loop injection to the extraction column. However, the maximum injection volume of conventional and commercial autosampler is typically below $1 \mathrm{~mL}$. Therefore, on-line SPE-LC-MS with LVI was performed by repeated draws and sample ejects from the same vial. For example, $1 \mathrm{~mL}$ aliquot (containing $100 \mu \mathrm{L}$ urine sample) was injected by execution of two sequential injections [24]. It is

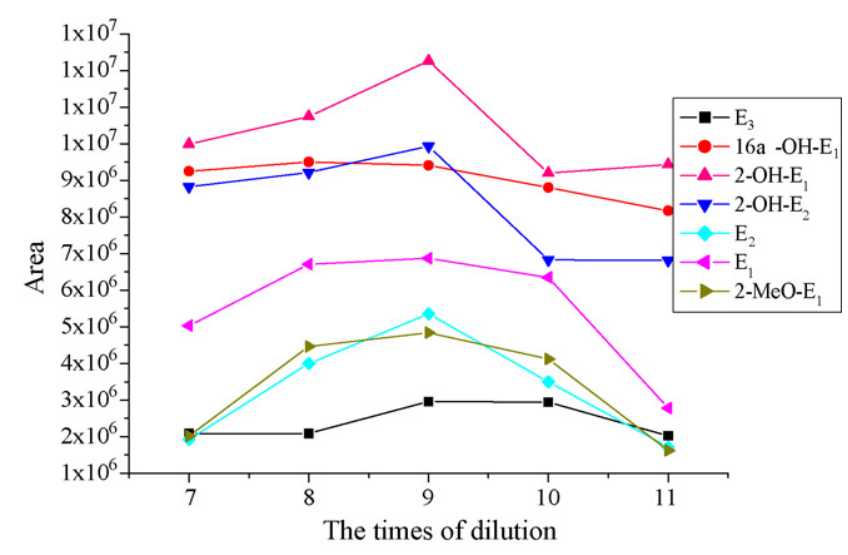

Fig. 3. Effect of the times of dilution on peak areas.

obvious that the method is not suitable for larger volume injection. To conquer the barrier, we directly used a pump to deliver sample under low flow-rate. Nevertheless, if the sample was directly loaded onto the RAM column, the anlaytes would be washed away to waste instead of retained on the extraction column. The reason was that the interaction between the analytes and stationary phase was weakened when high content of acetonitrile (ca. 67\%) in the sample. Consequently, the trap capability of pre-column decreased, which led to breakthrough of pre-column and low recovery. In order to efficiently trapping the analytes, the content of acetonitrile in the sample aliquot should be decreased. To resolve the problem, we added an on-line dilution line. The sample aliquot was diluted under high flow-rate and the content of acetonitrile in the sample aliquot sharply decreased. Therefore, it was very important to investigate the composition of mobile phase dilution and ratios.

\subsubsection{Optimization of dilution mobile phase}

According to previous research [20], $\mathrm{NH}_{4} \mathrm{Ac}$ could increase the solubility of protein in water. Therefore, $\mathrm{NH}_{4} \mathrm{Ac}$ solution was used as the dilution mobile phase, and concentrations ranging from 0 to $50 \mathrm{mmol} / \mathrm{L}$ were investigated. The optimal performance was obtained with $20 \mathrm{mmol} / \mathrm{L} \mathrm{NH}_{4}$ Ac solution as the dilution mobile phase, which further cleaned up the sample, reduced matrix effect, and increased the recovery due to the increase of protein solubility in salt solution by electrostatic interaction [25]. While increasing to $50 \mathrm{mmol} / \mathrm{L}$, the signal intensity of analytes rapidly decreased since residual $\mathrm{NH}_{4}$ Ac entered into MS which suppressed the ionization of analytes. As the studies carried out by Benijts indicated, even low concentrations of these buffers in the LC mobile phase resulted in extreme ion suppression [25]. Therefore, $20 \mathrm{mmol} / \mathrm{L} \mathrm{NH}_{4} \mathrm{Ac}$ solution was selected for the further experiment.

Then, the dilution ratios of 7-11 were studied from by changing the flow-rate of the dilution line, while the flow-rate of loading sample was fixed at $0.3 \mathrm{~mL} / \mathrm{min}$. Fig. 3 gives the response of analytes with changing the dilution ratios. It could be seen that 9 -fold, i.e. $2.7 \mathrm{~mL} / \mathrm{min}$ was the best ratio. That was, the loading sample contained about $6 \%$ acetonitrile after diluted 9 -fold. When lower flow-rate was used, a higher content of acetonitrile was in the extraction mobile phase, which weakened the retention of analytes on the pre-column and decreased recovery correspondingly. Under higher flow-rate, recovery would also be compromised once the analytes were washed out with mobile phase.

In addition, the dilution line increased the capacity of precolumn. For the traditional on-line method, the sample was transferred from the autosampler or loop injector to the extract column sandwiching by the mobile phase under the same flowrate as mobile phase. For example, $1 \mathrm{~mL}$ sample was loaded at 


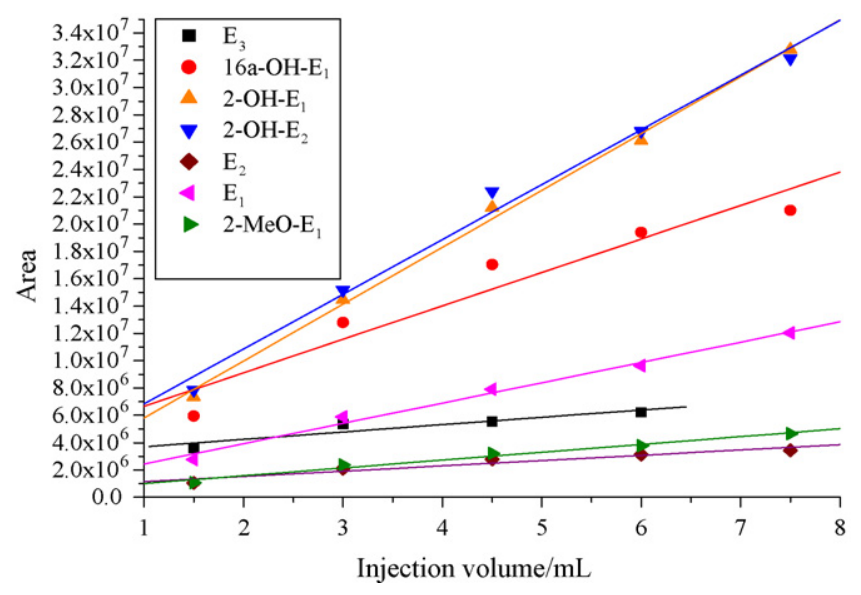

Fig. 4. The linear relation between peak areas of analytes and injection volumes.

the flow-rate of $3.0 \mathrm{~mL} / \mathrm{min}$, that was, the band of sample passed through the extraction column for about $0.3 \mathrm{~min}$. As a result, some analytes could not be retained in such a short time for the limitation of inter-phase mass transfer between the mobile phase and the stationary phase. They would be washed away to waste. However, when the sample after protein precipitation was delivered at low flow-rate, such as $0.3 \mathrm{~mL} / \mathrm{min}$, then it was diluted by mobile phase at $2.7 \mathrm{~mL} / \mathrm{min}$, finally loaded onto extraction column at the total flow-rate of $3.0 \mathrm{~mL} / \mathrm{min}$. It took $10 \mathrm{~min}$ to load the same amount of sample. The concentration of analytes in sample aliquot sharply decreased. Compared with traditional method, the sample was loaded onto the RAM pre-column at lower concentrations and for longer times. As a result, it increased the chance of analytes being retained by the hydrophobic inner surface, and the capacity of pre-column was enhanced. However, it did not prolong the time of sample preparation since the sample was simultaneously loaded and cleaned.

\subsubsection{Performance of the on-line liquid chromatography-mass spectrometry}

Although the extraction condition was optimized, some endogenous impurity still existed especially at weak retention range due to much polar matrices. The more sample that was injected; the more matrix components would be introduced into system. Lastly, to minimize the matrix effect and contamination of the ion optics by matrix components, an additional post-column 6-port switching valve was installed to divert only the analyte-containing effluents to the MS system [26]. In order to avoid damaging MS under high temperature when no aliquot entered, Acetonitrile aliquot was compensated and introduced into MS by another pump at flow-rate of $0.2 \mathrm{~mL} / \mathrm{min}$.

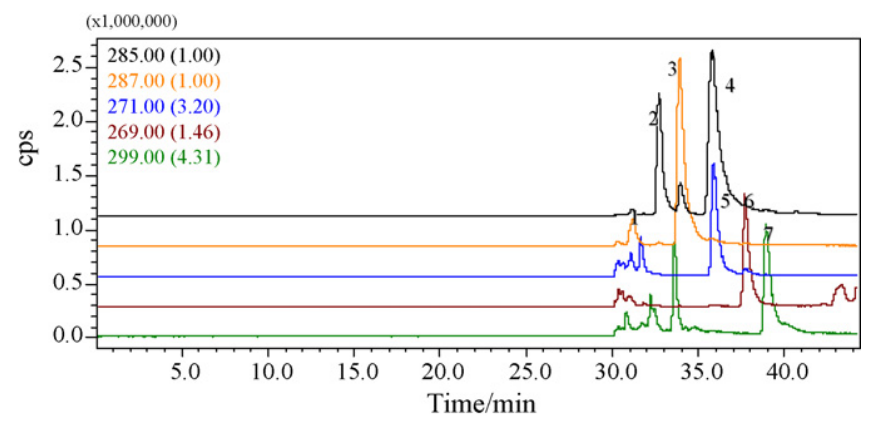

Fig. 5. Chromatogram of spiked urine sample. Peaks as in Fig. 3.

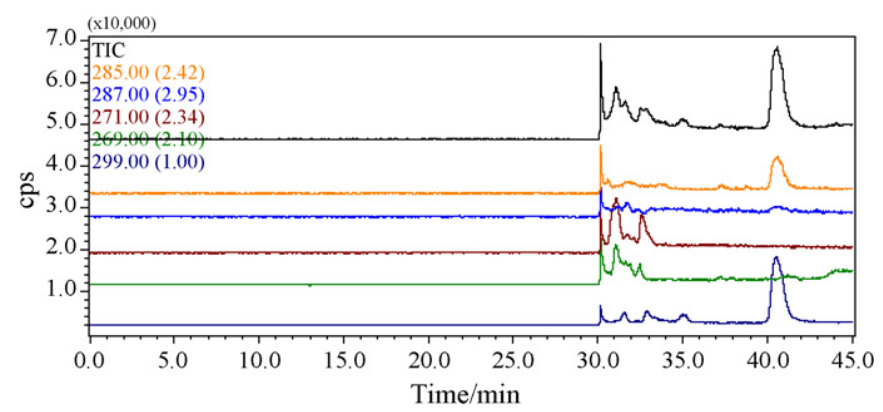

Fig. 6. The matrix effect of blank urine sample.

The whole scheme of on-line LC-MS is shown in Fig. 2 consisting of five pumps and two 6-port valves without autosampler. The on-line extraction approach described here was a hybrid sample preparation technique that varied itself from either protein precipitation or on-line solid-phase extraction. Besides protein precipitation, it added multi-dimensions of sample purification without consuming too much time because of the simultaneous loading, extraction, and washing procedures. For most other on-line methods, the pretreatment time was about 5 min or even longer $[15,20]$. After the sample was diluted by a high flow-rate mobile phase, it was loaded onto the pre-column and matrice so the proteins were washed out, then the valve was switched. The analytical mobile phase transferred the analytes from the pre-column to the analytical column; the analytes were separated and detected by MS.

In order to confirm the feasibility of the method, we first selected standard sample to investigate the performance of our system since matrix effect would be adverse effect when using real samples. $1.5 \mathrm{~mL}$ standard aliquots $(10 \mathrm{ng} / \mathrm{mL})$ were injected, loaded, separated and detected. Then, $10 \mu \mathrm{L}$ standard sample $(1.5 \mathrm{mg} / \mathrm{mL})$ was directly injected into the LC-MS without on-line concentration. The results indicated that the responses of all analytes with large volume and low concentration had no remarkable difference from those of traditional small volume and high concentration.

In addition, the relation between peak area of analytes and injection volume was investigated from 1.5 to $7.5 \mathrm{~mL}$ with increasing injection times of 5-25 min as shown in Fig. 4. The signal was exactly proportional to the injection volume. However, when the injection volume was increased to $7.5 \mathrm{~mL}$, the response of $E_{3}$ seriously biased from the linearity. Therefore, the data was not shown. These results of standard samples adequately proved the reliability of the on-line method to achieve LVI. In order to minimize the pollution of MS, matrix effect and obtain the acceptable time of sample preparation, $10 \mathrm{~min}$ injection times was chosen with the injection volume of $3 \mathrm{~mL}$ sample aliquot, corresponding to $1 \mathrm{~mL}$ urine. Fig. 5 shows the typical selection ion monitor chromatogram of spiked urine sample. Although some impurities existed, reliable quantification could be obtained by SIM mode since no interference peaks existed. In addition, compared of low volume injection, peak broadening was observed especially for $2-\mathrm{OH}-\mathrm{E}_{2}$ and $2-\mathrm{OH}-\mathrm{E}_{1}$. However, no seriously adverse influence was seen in the quantification of analytes.

\subsubsection{Matrix effect}

For LC-MS system, one of the main causes of matrix effect is believed to be the co-elution of analytes and matrice. This was the reason that the use of long gradient program prolonged the retention times of analytes, while reducing ionization suppression and/or matrix interference. Most estrogens are efficient separated from matrices except for $\mathrm{E}_{3}$ and $16 \alpha-\mathrm{OH}-\mathrm{E}_{1}$. In addition, the postcolumn 6-port switching valve not only decreased the pollution by 
Table 2

The matrix effect of the on-line LC-MS method

\begin{tabular}{|c|c|c|c|c|c|c|}
\hline Analytes & Areas of standard & Areas of pre-spiked & Areas of post-spiked & $\% \mathrm{ME}$ & $\%$ RE & \%PE \\
\hline $\mathrm{E}_{3}$ & 2813550 & 2514165 & 2522334 & 89.7 & 99.7 & 89.359 \\
\hline $16 \alpha-\mathrm{OH}-\mathrm{E}_{1}$ & 8915364 & 6333871 & 6233982 & 69.9 & 102 & 71.04 \\
\hline $2-\mathrm{OH}-\mathrm{E}_{2}$ & 7441354 & 6570553 & 6575513 & 88.4 & 99.9 & 88.298 \\
\hline $2-\mathrm{OH}-\mathrm{E}_{1}$ & 6580159 & 5287213 & 5720612 & 86.9 & 92.4 & 80.35 \\
\hline $\mathrm{E}_{1}$ & 753960 & 754959 & 747775 & 99.2 & 101 & 100 \\
\hline $2-\mathrm{MeO}-\mathrm{E}_{1}$ & 4701443 & 3830108 & 4019403 & 85.5 & 95.3 & 81.467 \\
\hline
\end{tabular}

impurity but also cleaned up the MS, which contributed to reducing matrix effect.

After optimization and improvement of program, two measures to evaluate matrix effect of the on-line LC-MS method. Firstly, the baseline containing blank sample effluents was compared with that obtained with mobile phase. When the valve 2 was at the position 2 (a), acetonitrile was enter into MS, while after the valve 2 was diverted, the effluents containing urine matrices were introduced to MS. As shown in Fig. 5, the baseline noise increased obviously when the valve 2 was diverted and sample effluents were introduced to MS at $30 \mathrm{~min}$, which would decrease the signal to noise of analytes. Based on this phenomenon, we think that matrix effect shows ionization suppression for the on-line method (Fig. 6).

In addition, according to report, matrix effect (\%ME), recovery (\%RE) and process efficiency (\%PE) were calculated as follows [27]:

$\% \mathrm{ME}=\frac{\text { Area of post-extraction spiked }}{\text { Area of standard }} \times 100 \%$

$\% \mathrm{RE}=\frac{\text { Area of pre-extraction spiked }}{\text { Area of post-extraction spiked }} \times 100 \%$

$\% \mathrm{PE}=\frac{\text { Area of pre-extraction spiked }}{\text { Area of standard }} \times 100 \%=\frac{\% \mathrm{ME} \times \% \mathrm{RE}}{100 \%}$

Therefore, the $100 \mathrm{ng} / \mathrm{mL}$ samples were spiked standard sample before and after adding acetonitrile to the urine. At the same time, the $100 \mathrm{ng} / \mathrm{mL}$ standard sample was determined. These peak areas of estrogens are shown in Table 2. The two different kinds of spiked samples indicated similar retention behavior and response. The recoveries were close to $100 \%$, showed that the analytes could be separated from protein, and co-precipitation phenomenon did not occur. In addition, we did not found residual estrogens in precolumn and analytical column. That is, the carryover of the system is negligible, and the \%ME could represent the matrix effect of whole system showing slight ion suppression and good \%PE. Process efficiency summarizes the efficiency of sample preparation (recovery) and analyte ionization (matrix effect). Therefore, process efficiency is suitable quantity for assessing the overall performance of an analysis method.

\subsection{Validation of the method}

For further validation of method for real samples, the linear dynamic range, accuracy, precision, LODs and LOQs were evaluated. To avoid the interference of endogenous impurities, we selected urines of healthy adult men as samples, in which estrogen and their metabolites were at the $\mathrm{pg} / \mathrm{mL}$ level [28]. For the blank urine, no analtyes were detected. Calibration curves covered the range of $1-500 \mathrm{ng} / \mathrm{mL}$ with correlation coefficients over 0.99 . When the concentration of analytes increased from 500 to $1000 \mathrm{ng} / \mathrm{mL}$, the responses did not obviously increase. It indicated the experiment with $1000 \mathrm{ng} / \mathrm{mL}$ was over the capacity of RAM pre-column. Accuracy and precision experiments were carried out by spiking samples at three different concentrations of estrogens. The peak areas obtained were compared with those obtained from the standard solutions. The results are shown in Table 3. The process efficiency ranged from 70.2 to 106 with RSDs less than $15 \%$ with a few exceptions. The whole process of analysis was automatic except protein precipitation. We thought that the high RSDs mainly resulted from matrix effect, especially for $\mathrm{E}_{3}$ and $16 \alpha-\mathrm{OH}-\mathrm{E}_{1}$, which showed more polarity and had similar retention behavior to the endogenous compounds, exhibited the lowest recoveries and the highest RSDs due to ion suppression. On the whole, it was thought that the accuracy and precision of the spiked samples were acceptable for the analysis of LVI containing most endogenous compounds. For conventional injection volume, some new methods often show similar value $[4,26]$ meaning that matrix effect had not seriously effected the quantification of estrogens. The LODs and LOQs of estrogens were at the low ppb levels as shown in Table 4.

\subsection{Comparison of traditional methods}

First, it was compared with on-line LC-MS method without dilution line. When the dilution line was removed and the sample was directly delivered by pump and loaded without dilution, as expected and shown in Fig. 7A, the analytes were not retained by the RAM column, and even more sample was loaded. The reason was that the loaded aliquot contained high content of organic solvent.

For most on-line LC-MS methods with TFC or RAM columns, the injection volume of biofluid was set at $100 \mu \mathrm{L}$. In order to

Table 3

The \%PE and RSD of spiked urine at three concentration

\begin{tabular}{|c|c|c|c|c|c|c|}
\hline \multirow[t]{3}{*}{ Analyte } & \multicolumn{6}{|c|}{$\% \mathrm{PE}(\mathrm{RSD}) n=5$} \\
\hline & \multicolumn{2}{|l|}{$5 \mathrm{ng} / \mathrm{mL}$} & \multicolumn{2}{|l|}{$50 \mathrm{ng} / \mathrm{mL}$} & \multicolumn{2}{|l|}{$500 \mathrm{ng} / \mathrm{mL}$} \\
\hline & Intra & Inter & Intra & Inter & Intra & Inter \\
\hline$E_{3}$ & $90.5(11.3)$ & $106(13.0)$ & $74.7(11.5)$ & $75.9(15.0)$ & $70.4(8.18)$ & $70.2(14.7)$ \\
\hline $16 \alpha-\mathrm{OH}-\mathrm{E}_{1}$ & $82.7(14.8)$ & $76.3(17.0)$ & $73.1(12.5)$ & $73.7(13.1)$ & $73.2(9.12)$ & $70.2(12.9)$ \\
\hline $2-\mathrm{OH}-\mathrm{E}_{2}$ & $95.4(10.6)$ & $88.3(11.7)$ & $101(7.07)$ & $90.9(8.20)$ & $97.3(8.21)$ & $104(7.90)$ \\
\hline $2-\mathrm{OH}-\mathrm{E}_{1}$ & $95.1(12.6)$ & $94.2(13.4)$ & $102(10.6)$ & $106(14.5)$ & $101(10.2)$ & $94.3(10.5)$ \\
\hline $\mathrm{E}_{2}$ & $92.5(11.7)$ & $85.4(12.0)$ & $98.1(6.95)$ & $90.3(12.0)$ & $93.1(9.10)$ & $94.9(8.51)$ \\
\hline$E_{1}$ & $82.0(13.2)$ & $89.4(15.3)$ & $98.2(6.03)$ & $94.3(12.2)$ & $88.3(6.70)$ & $92.8(13.6)$ \\
\hline $2-\mathrm{MeO}-\mathrm{E}_{1}$ & - & - & $95.8(5.82)$ & $94.1(8.76)$ & $95.4(6.68)$ & $105(9.90)$ \\
\hline
\end{tabular}


Table 4

LODs and LOQs (ng/mL) of estrogens in urine with large volume injection

\begin{tabular}{llllll}
\hline Analyte & LODs & LOQs & Analyte & LODs & LOQs \\
\hline $\mathrm{E}_{3}$ & 1 & 2 & $\mathrm{E}_{2}$ & 0.5 & 1 \\
$16 \alpha-\mathrm{OH}-\mathrm{E}_{1}$ & 1 & 2 & $\mathrm{E}_{1}$ & 0.5 & 1 \\
$2-\mathrm{OH}-\mathrm{E}_{2}$ & 0.3 & 1 & $2-\mathrm{MeO}-\mathrm{E}_{1}$ & 2 & 8 \\
$2-\mathrm{OH}-\mathrm{E}_{1}$ & 0.3 & 1 & & & \\
\hline
\end{tabular}

further confirm the advantage of this method, LODs and LOQs of traditional on-line LC-MS method were determined using RAM as the pre-column and an injection volume of $100 \mu \mathrm{L}$ (Table 5). Compared to the data with shown in Table 3, it can be seen that the LODs and LOQs of the new method established decreased 5-10fold. In addition, it was compared with the traditional off-line method with nitrogen drying and reconstitution. $1 \mathrm{~mL}$ urine was precipitated by $2 \mathrm{~mL}$ acetonitrile; then the supernatant was transferred, dried and reconstituted to $1 \mathrm{~mL} .10 \mu \mathrm{L}$ was injected by the autosamper and analyzed. As shown in Fig. 7B, LODs of analytes were close to $100 \mathrm{ng} / \mathrm{mL}$. These data indicate that the sensitivity of the new method using LVI was improved of $1-2$ orders of magnitude, compared with traditional off-line and on-line methods, although the improvement was not exactly proportional to the increases of injection volumes, which may result from ion suppression.

\subsection{Column lifetimes}

The RAM and analytical columns were regularly washed with formic acid solution. No noticeable increase in backpressure was observed after a total of 300 injections. This is attributed to the online extraction process including several factors as follows: first, most protein was removed by protein precipitation. Then the sample was diluted by solution containing salt, which could increase the solubility of the protein in mobile phase. Finally, the RAM pre-
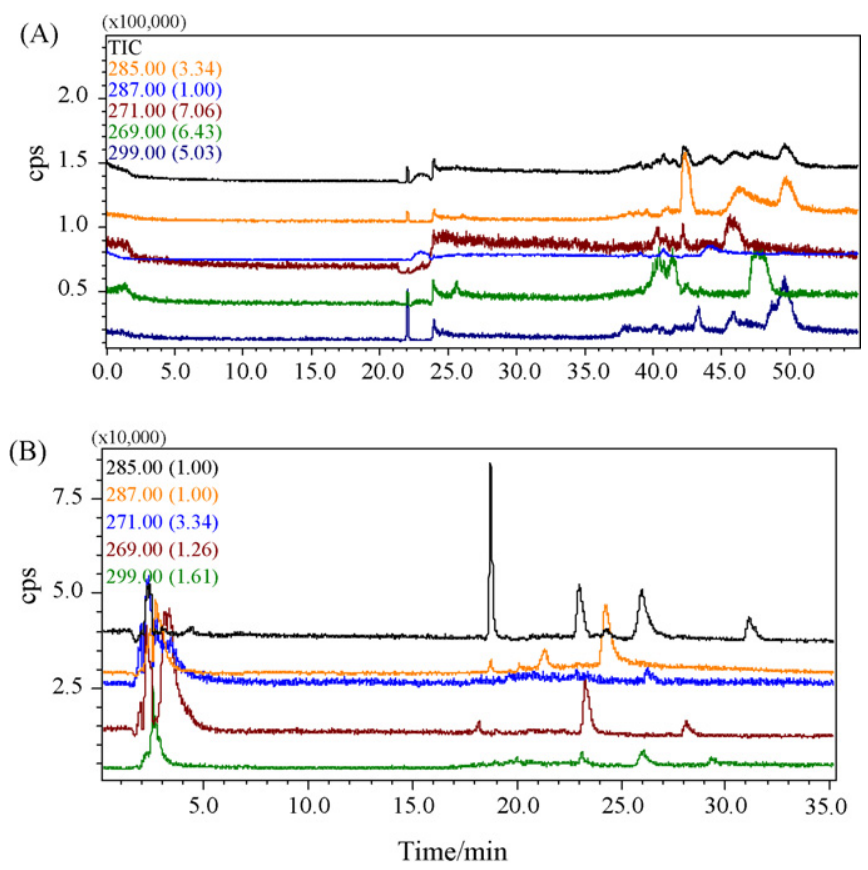

Fig. 7. Chromatogram of estrogens with traditional on-line and off-line methods. (A) On-line method without dilution line by injection standard sample $100 \mathrm{ng} / \mathrm{mL}$. The solvent of standard sample was acetonitrile-water (2:1). (B) Off-line method with nitrogen dryness and reconstitution after de-protein by acetonitrile with spiked $100 \mathrm{ng} / \mathrm{mL}$ urine (injection volume $10 \mu \mathrm{L}$ ).
Table 5

LODs and LOQs (ng/mL) of estrogens in urine with traditional on-line LC-MS

\begin{tabular}{llrllr}
\hline Analyte & LODs & LOQs & Analyte & LODs & LOQs \\
\hline $\mathrm{E}_{3}$ & 5 & 10 & $\mathrm{E}_{2}$ & 4 & 8 \\
$16 \alpha-\mathrm{OH}-\mathrm{E}_{1}$ & 5 & 10 & $\mathrm{E}_{1}$ & 4 & 8 \\
$2-\mathrm{OH}-\mathrm{E}_{2}$ & 3 & 8 & $2-\mathrm{MeO}-\mathrm{E}_{1}$ & 8 & 50 \\
$2-\mathrm{OH}-\mathrm{E}_{1}$ & 3 & 8 & & & \\
\hline
\end{tabular}

column could further get rid of residual protein due to size exclusion interaction.

\section{Conclusions}

Using a unique column switching system with a RAM precolumn and a dilution line, a rapid, simple and automated on-line LC-MS method to improve the analytical sensitivity of trace compound in urine with LVI was developed. Sample preparation simply involved protein precipitation by acetonitrile. An LC pump was used to deliver the sample and an on-line dilution line was added to sharply decrease the content of acetonitrile in sample, which markedly increased the trap capability of the pre-column and achieved large volume urine injections. Compared with other on-line methods published for the analysis of biofluid, to our knowledge, this was the first time that $1 \mathrm{~mL}$ urine could be loaded, enriched and analyzed by on-line LC-MS. The feasibility of the system was confirmed by the extraction and determination of 7 estrogens in spiked human urine. The system improved the sensitivity by 1-2 orders of magnitude compared with those of other conventional off-line and on-line methods. We believe that the method provides a simple and useful alternative to improve the sensitivity and LODs of on-line LC-MS method for high throughput screening and determination of trace compounds in biofluid including serum, plasma and so on. Lastly, LC-MS/MS and internal standard are recommended to further improve the sensitivity and minimize ion suppression combined with sufficient chromatographic separation.

\section{Acknowledgements}

This work was supported by the Major Research Program of Chinese Academy of Sciences (KZCX3-SW-432) and the National Natural Science Foundation of China (Grant Nos. 20437020 and 20575073).

\section{References}

[1] S.S.-C. Tai, M.J. Welch, Anal. Chem. 76 (2004) 1008

[2] M.B. Satterfield, L.T. Sniegoski, M.J. Welch, B.C. Nelson, Anal. Chem. 75 (2003) 4631.

[3] E. Kindt, Y. Shum, L. Badura, P.J. Snyder, A. Brant, S. Fountain, G. Szekely-Klepser, Anal. Chem. 76 (2004) 4901.

[4] A. Kärrman, B.V. Bavel, U. Järnberg, L. Hardell, G. Lindström, Anal. Chem. 77 (2005) 864.

[5] G. Rule, M. Chapple, J. Henion, Anal. Chem. 73 (2001) 439.

[6] M. Li, Y. Alnouti, R. Leverence, H.G. Bi, A.I. Gusev, J. Chromatogr. B 825 (2005) 152.

[7] P. Jacob, M. Wilson, L. Yu, J. Mendelson, R.T. Jones, Anal. Chem. 74 (2002) 5290.

[8] L. Ynddal, S.H. Hansen, J. Chromatogr. A 1020 (2003) 59.

[9] Z. Kuklenyik, L.N. Needham, A.M. Calafat, Anal. Chem. 77 (2005) 6085

[10] H. Zeng, J.T. Wu, S.E. Unger, J. Pharam. Biomed. Anal. 27 (2002) 967.

[11] J.T. Wu, H. Zeng, M. Qian, B.L. Brogdon, S.E. Unger, Anal. Chem. 72 (2000) 61.

[12] Y. Alnouti, K. Srinivasan, D. Waddell, H. Bi, O. Kavetskaia, A.I. Gusev, J. Chromatogr. A 1080 (2005) 99.

[13] R. Plumb, G. Dear, D. Mallett, J. Ayrton, Rapid Commun. Mass Spectrom. 15 (2001) 986

[14] A. Vintiloiu, W.M. Mullett, R. Papp, D. Lubda, E. Kwong, J. Chromatogr. A 1082 (2005) 150.

[15] B. Christiaens, M. Fillet, P. Chiap, O. Rbeida, A. Ceccato, B. Streel, J.D. Graeve, J. Crommen, P. Hubert, J. Chromatogr. A 1056 (2004) 105.

[16] S.R. Needham, M.J. Cole, H.G. Fouda, J. Chromatogr. B 718 (1998) 87. 
[17] S. Briem, B. Pettersson, E. Soglund, Anal. Chem. 77 (2005) 1905.

[18] P. Molander, A. Thomassen, L. Kristoffersen, T. Greibrokk, E. Lundanes, J. Chromatogr. B 766 (2001) 77.

[19] J.Y. Ma, Y.L. Gu, B. Chen, S.Z. Yao, Z.N. Chen, J. Chromatogr. A 1113 (2006) 55.

[20] M. Liu, Y. Hashi, F.Y. Pan, J.G. Yao, G.Q. Song, J.-M. Lin, J. Chromatogr. A 1133 (2006) 142

[21] C. Polson, P. Sarkar, B. Incledon, V. Raguvaran, R. Grant, J. Chromatogr. B 785 (2003) 263

[22] S. Souverain, S. Rudaz, J.L. Veuthey, J. Pharm. Biomed. Anal. 35 (2004) 913.
[23] S. Souverain, S. Rudaz, J.L. Veuthey, J. Chromatogr. A 1058 (2004) 61.

[24] X.Y. Ye, Z. Kuklenyik, L.L. Needham, A.M. Calafat, Anal. Chem. 77 (2005) 5407.

[25] T. Benijts, R. Dams, W. Günther, W. Lambert, A.D. Leenheer, Rapid Commun Mass Spectrom. 16 (2002) 1358.

[26] R. Pascoe, J.P. Foley, A.I. Gusev, Anal. Chem. 73 (2001) 6014.

[27] A. Kruve, A. K"unnapas, K. Herodes, I. Leito, J. Chromatogr. A 1187 (2008) 58.

[28] X. Xu, T.D. Veenstra, S.D. Fox, J.M. Roman, H.J. Issaq, R. Falk, J.E. Saavedra, L.K. Keefer, R.G. Ziegler, Anal. Chem. 77 (2005) 6646. 